\title{
Factors influencing control of the epidemic in Egypt : Case of mapping vulnerability index for the spread of COVID-19
}

\section{Original Article}

\author{
Irene Fahim ${ }^{1,2}$, Nahla Hazem², Tawfik Ismail ${ }^{3,4}$, Dina El kayaly ${ }^{5,6}$ \\ ${ }^{1}$ Industrial Engineering, SESC Centre, Nile University, ${ }^{2}$ Management of Technology, \\ Nile University, ${ }^{3}$ Wireless Intelligent Networks Centre, Nile University, ${ }^{4}$ National \\ Institute of Laser Enhanced Sciences, Cairo University, ${ }^{5}$ International Business, New \\ Giza University, ${ }^{6}$ Head of Marketing and Market Research, Edge for Training and \\ Consulting, Cairo, Egypt
}

Keywords:

Blockchain, COVID-19, SPSS, mapping, AI.

\section{Corresponding Author:}

Irene Samy Fahim, Industrial Engineering, Nile University, Tel: 0100182221, Email: isamy@nu.edu.eg

\begin{abstract}
The development of data analytics helps the governorates to identify strategies and procedures to minimize the negative impacts of COVID-19. Several epidemiological models are employed to monitor and understand the spread of diseases and their impacts on countries. This article aims to present the relative risks faced by each country so that response efforts can be more effectively focused during the different phases of the pandemic. It analyses important factors for countries through different simulated modelling. Geographic Information Systems (GIS) mapping was also presented to determine and classify disease transmission susceptibility and analyse disease transmission decisions. Furthermore, this article aims to provide a detailed overview of the possibilities that Artificial Intelligence (AI) and Big Data present when it is coping with the COVID 19 pandemic. It also uses blockchain technology for recording, verifying, and authorizing data when carrying out a series of transactions. AI is a powerful technology that can help tackle the threat of the COVID 19 pandemic by using various techniques, including machine learning and natural language processing.
\end{abstract}

\section{INTRODUCTION}

The novel coronavirus extends all over the world. The outbreak has victimized several people. In just over 5 months, it has transmitted to over 100 nations, infecting more than $115,768,952$ people, and taking over $2,571,785$ lives as rapidly as the COVID-19 virus is growing, physicians, academics and researchers are making massive efforts to find preventative and healing measures (COVID - 19 a direct counter for injuries around the world, $2020)^{[1]}$. The main cause for this unprecedent spread is that droplets triggered by coughing or sneezing of an reaches the nose, eyes, or mouth of another.

It is also conceivable that the virus will spread through the feces. There is also controversy about how long after a person coughs or sneezes, the virus may remain in the air $^{[2-4]}$. In the process of coronavirus spreading control by governments and health organizations, they need all the assistance that they can receive, including statistical analyses. They are very important to manage spreads, to diagnose patients, to disinfect areas and to accelerate the process to cure COVID-19. However, the most accurate methods that might be used to combat a coronavirus outbreak are computer science, modeling simulation and mapping techniques ${ }^{[5-6]}$.

The outbreak of the COVID-19 virus is associated with many reasons such as age, immunity, health system, population, education, technology, and other key factors for the virus spread. Most scientists used to track all factors, set their values and change each factor simultaneously. This approach is unrealistic, and it doesn't think include interactions between different factors; beside the fact that it requires countless trials. Based on this fact, we needed a different more realistic approach.

\section{METHODOLOGY}

The primary stage was identifying the risk factors that affected the fast spread and transmission of the pandemic COVID 19 in Egypt. The authors consulted the literature and compiled a long list of variables. The most recurrent 16 factors that the authors believe, might affect the transmission of COVID 19 across Egyptian governorates were selected. Factors were derived from CAPMAS database, General Agency for Public Mobilization and Statistics, and 
the World Health Organization (WHO) website. The risk factors were classified into three main categories: demographic factors, environmental factors, and healthcare factors as shown in Table 1. The demographic factors were categorized into urban population, density, illiteracy rate and unemployment rate. For the environmental factors they included lack of sewage and water, informal-housing, poverty rate and the number private vehicles (which represented the social distance aspect in this research). The health conditions involved the number of public hospitals, number of beds in public and isolation hospitals, number of ICU beds for adults and kids, Number of registered doctors and number of ambulance cars.

Table 1: Factors affecting the number of COVID-19 cases $^{[7]}$

\begin{tabular}{|c|c|}
\hline Dimension & Indicator \\
\hline \multirow{5}{*}{ Demographic Factors } & Urban population \\
\hline & Density rate \\
\hline & \\
\hline & Illiteracy rate \\
\hline & Unemployment rate \\
\hline \multirow{5}{*}{ Environmental Factors } & \# of Houses not connected to sewage \\
\hline & \# of Houses not connected to water \\
\hline & \# of Informal housing \\
\hline & Poverty rate \\
\hline & \# of Privately owned vehicles \\
\hline \multirow{7}{*}{ Healthcare factors } & \# of Public hospitals \\
\hline & \# of Beds at public hospitals \\
\hline & $\#$ of Beds for isolation \\
\hline & \# of ICU beds \\
\hline & \# of ICU beds for kids \\
\hline & \# of Registered doctors \\
\hline & \# of Ambulance cars \\
\hline
\end{tabular}

The authors started by identifying the risk factors (16 variables) that affected the fast spread and transmission of the pandemic COVID-19 in Egypt. They were able to find, which governorates are more vulnerable across the various governorates of Egypt to the risk factors allocated. The geographic information system (GIS) was successful than others since it has an accurate geographic information recordkeeping. Determining the relative threats that face every governorate will help direct the distribution of resources as the pandemic grows. Furthermore, the authors used one of the composite index tools which is the exploratory factor analysis (EFA) to minimize the several individual variables in a fewer number of variables based on the importance and the weight for each factor determined. EFA is often recommended when researchers have no hypotheses about the nature of the underlying factor structure of their measure, which was the case in this study. Besides, the EFA estimates factors, underlying constructs that cannot be measured directly. Additionally, the authors needed to find the most significant variable among the 16 variables besides calculating the weight of each factor that was previously calculated. The most significant factor was 
allocated using analysis of variance (ANOVA) statistical analysis and a stepwise regression analysis was performed afterwards to validate the ANOVA analysis. In order to present the contribution of the paper and to integrate the different development models, we summarized the work done in the following diagram.

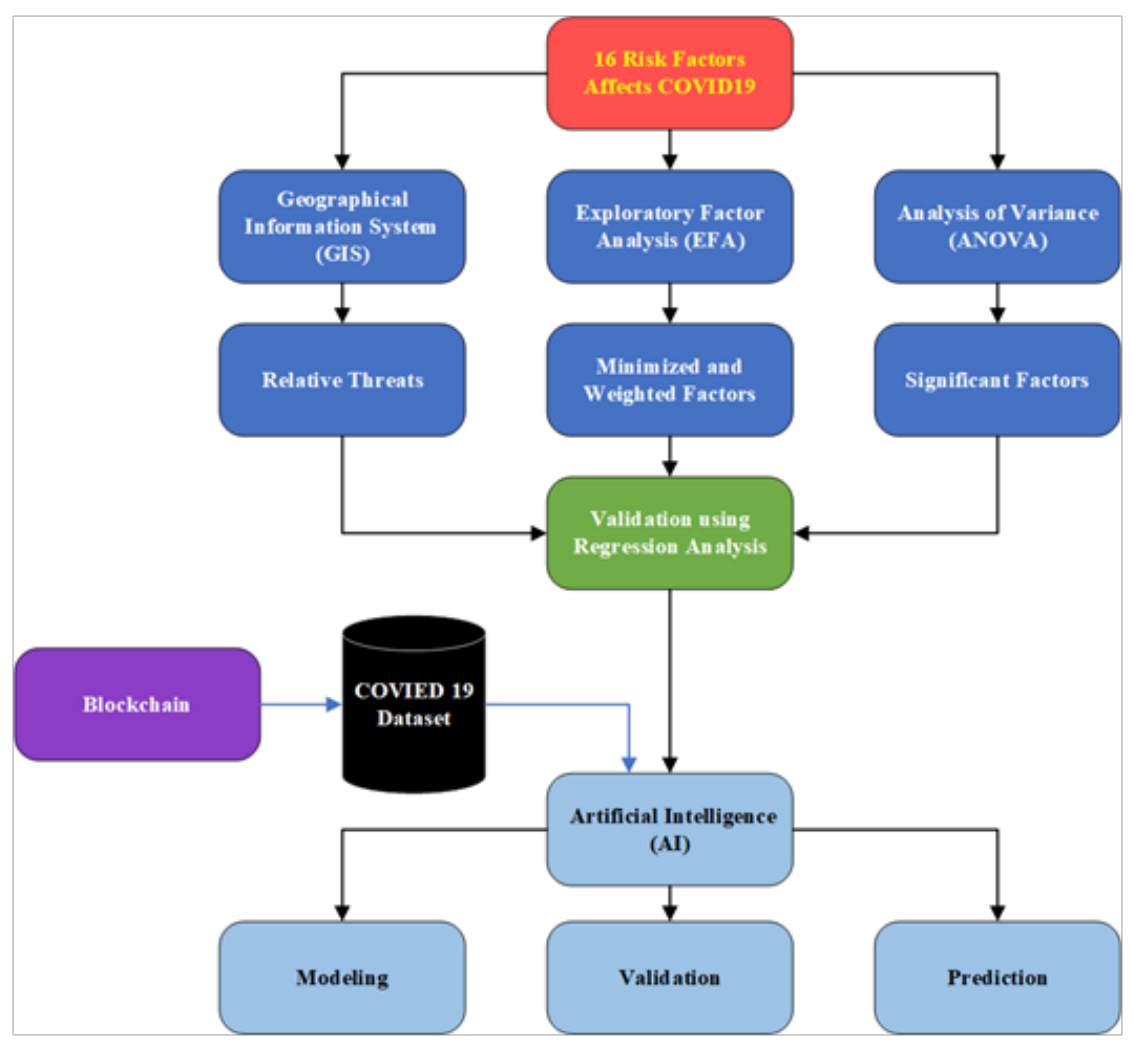

Fig. 1: Overall integrated structure for the developed methodology

\section{VARIOUS DATA ANALYTIC TOOL}

Data analytics is the science of analysing raw data leading to information-based decisions, many of its techniques and processes have been automated. During epidemics, high variety datasets should be assembled from originally independent datasets such as adding environmental and demographic data to typical healthcare data to better understand the current situations. Also, data analytics are used in different healthcare applications such as medical insurance, clinical trials, population health management. There are many tools used with data analytics such as Geographic Information Systems (GIS) mapping, Professional Statistical Analysis using SPSS, Big Data analysis using Python.

\section{III.1. GIS mapping}

GIS technology can serve healthcare management during epidemics. The most famous example is the generation of layers of data displaying all kinds of variables that are called risk factors to advise and help decision makers ${ }^{[8]}$. GIS technologies can be used for rapid and real-time exchanging and upgrading of information that leads to improved decision-making using better visualized layered complex data, recognizing at-risk or underserved communitieswithin the society, better resource distribution, planning activities and cost savings and improving communications during a crisis ${ }^{[9]}$. The ArcMap software was used in this study. It is considered as one of the main components of Esri's ArcGIS group. It allows creating and editing GIS datasets for the study area and permits assigning symbols and generating maps designs for publication and printing. To generate the maps that graphically show the comparative levels of vulnerability through the governorates in Egypt, certain data should be inserted in the software. The Shapefile of Egypt which is a simple format for the storage of the geometric location and assigning data of geographical characteristics. ESRI introduced the shapefile format for ArcGIS software.

\section{III.2. SPSS}

Statistical Package for the Social Sciences (SPSS) software offers simple statistical features such as frequency, bivariate statistics, and cross-tabulation. In this study bivarian statistics were obtained through an analysis of variance (ANOVA), means, correlations and 
nonparametric analyses and numerical predictions in the form of a linear regression equation which contributed to the final model being fitted accordingly, minimal errors, and a lack of fit ${ }^{[10]}$. It is one of the most known statistical analysis packages that uses various algorithms to classify clusters, and conduct regression analysis ${ }^{[11]}$. It helped the authors answering the following questions: is there a significant relationship between "what we want to measure' and set of data that predicts it? This question shows the regression that helps uncovering areas that needs improvements and guide effort optimization. Regression studies are excellent tools to predict the future trends. Are the data similar or there is a significant difference? This was the hypothesis testing that aided the authors in comparing data to a pre-defined hypothesis and predict the risk or uncertainty through Monte Carlo simulations that uses probability modeling to help predict risk and uncertainty ${ }^{[12]}$. However, it was essential in this research to combine the individual indicators into a single measure to calculate the vulnerability index for the spreading of COVID-19 across Egypt. A composite indicator, which represents a model of several dimensions, was drawn up by compiling individual indicators into a single index. In several different indicators, they are simpler to understand than trying to find a particular pattern. In view of supporting decision-makers, composition metrics have proven useful in the ranking countries and summarize multi-dimensional issues $^{[13]}$.

\section{III.3. Composite Index Analysis}

A composite index is a statistical combination of many factors to create an individual number ${ }^{[14]}$. In order to minimize several individual parameters in a fewer amount of variables, authors used exploratory factor analysis (EFA). The variables were also orthogonal (i.e.Uncorrelated) using Varimax rotational technique, avoiding multiple collinearity problems when evaluating regressions. The EFA generated three indices that are not identically grouped similar to the groups identified by the literature. The authors named them:

- Demographic and general healthcare conditions

- Environmental conditions

- Critical care conditions

In this analysis, the composite index was used to demonstrate how different variables are modified and how the weight for each factor is determined. It was accomplished by converting correlated original variables, using the covariance matrix, into a new set of uncorrelated variables. The new factors were linear combinations of the original variables that indicate the amount of variance that the original variables represent. The correlations between the input variables are big enough for most variance data sets to be referred to as the first few new variables called the principal components account (PCA). In summary, PCA requires the discovery of the eigenvalues covariance matrix values of the sample. The eigenvalue shows the variation in the data, how the data are distributed. Thus, the eigenvector with the highest eigenvalue is the key component. Although, PCA is an extremely useful tool for examining the correlation structure of variables groupings, ETA analysis was used as an extra tool to thoroughly examine the relationship structure of groups of variables, but it was also used to thoroughly examine the relationships between the sub-indicators and prevent redundancies ${ }^{[13]}$. XLSTAT statistical software was also used to calculate the PCA as a third tool for verification of data. It provides a complete and flexible PCA analysis to gain a deep insight into the data. It measures the distribution of a collection of data around its mean value is calculated and the directions of the two random variables. It also helps to imagine observations in 2- or 3-dimensional spaces to distinguish observations that are uniform or nonconform. This tool has been helpful in assigning high-variance variables that perform stronger output roles. Authors were able to determine the contributions which represent the degreeto which the corresponding PCA axis has been supported by each of the variables ${ }^{[15]}$.

\section{RESULTS AND DISCUSSIONS}

\section{IV.1. Decision supported by data analytic tools}

Keeping in mind the above-mentioned tools, the authors havedescribed in this section a series of vital decisions that needed to be taken as the epidemic continues to evolve. These decisions can be divided into 3 sections: (1) resource management decisions and risk assessments; (2) disease transmission decisions and (3) long-stay decisions, in this specific order.

\section{IV.2. Decisions affecting Assessing Vulnerability}

The authors have very limited information about the transmission pattern of COVID 19, and weather demographic factors such as density or economic factors such as poverty or even health factors such as \# of ICU units in a certain governorate, these factors have a significant impact on the number of infected people in a certain country. This study reviews the relative risks of the recent COVID 19 in different Egyptian governorates $^{[15]}$. The authors were able to find, which governorates are more vulnerable across the various governorates of Egypt.Figures 2 and 3 represent a set of maps graphically reflecting relative levels of vulnerability throughout Egypt using GIS maps. Table 2 shows the governates and their corresponding numbers on the GIS map. 
Table 2: Egypt's governates and their corresponding numbers GIS map

\begin{tabular}{|cccc|}
\hline$\#$ & Governorate & $\#$ & Governorate \\
\hline 1 & Matrouh & 15 & Cairo \\
\hline 2 & Luxor city & 16 & Elfayoum \\
\hline 3 & Kafr Elsheikh & 17 & Elghrbia \\
\hline 4 & Qena & 18 & Elsharkia \\
\hline 5 & South Sinai & 19 & Elsuez \\
\hline 6 & North Sinai & 20 & Eldakhlia \\
\hline 7 & Suhag & 21 & Elgiza \\
\hline 8 & Domiate & 22 & Elbouhyra \\
\hline 9 & Bort Said & 23 & Red Sea \\
\hline 10 & Bani Souef & 24 & Elismalia \\
\hline 11 & Elwadi Elgadeed & 25 & Alexandria \\
\hline 12 & Elmenia & 26 & Assuit \\
\hline 13 & Elmonoufia & 27 & Aswan \\
\hline 14 & Elkalubia & \\
\hline
\end{tabular}

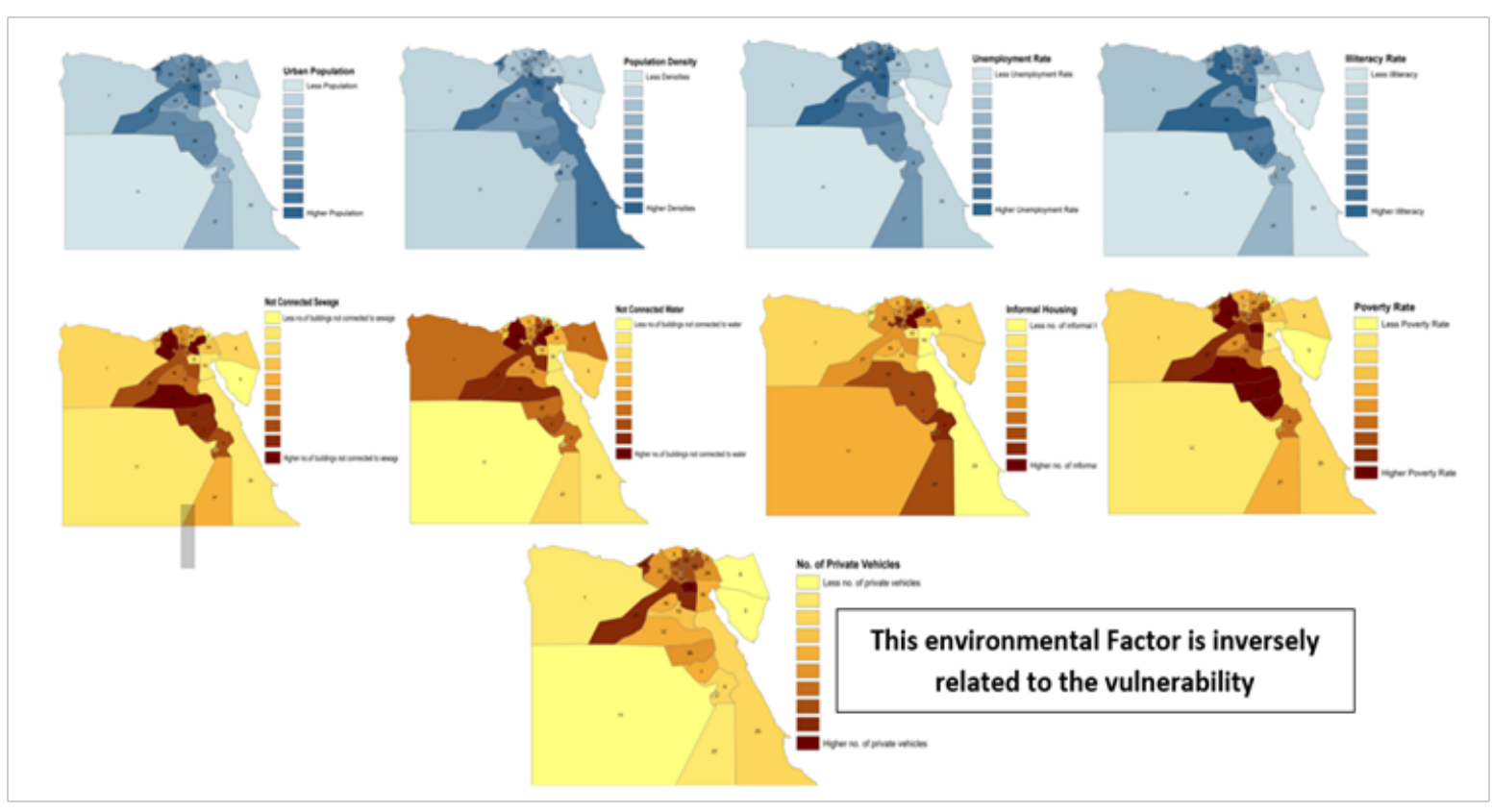

Fig. 2: Demographic and environmental levels of vulnerability across Egypt 


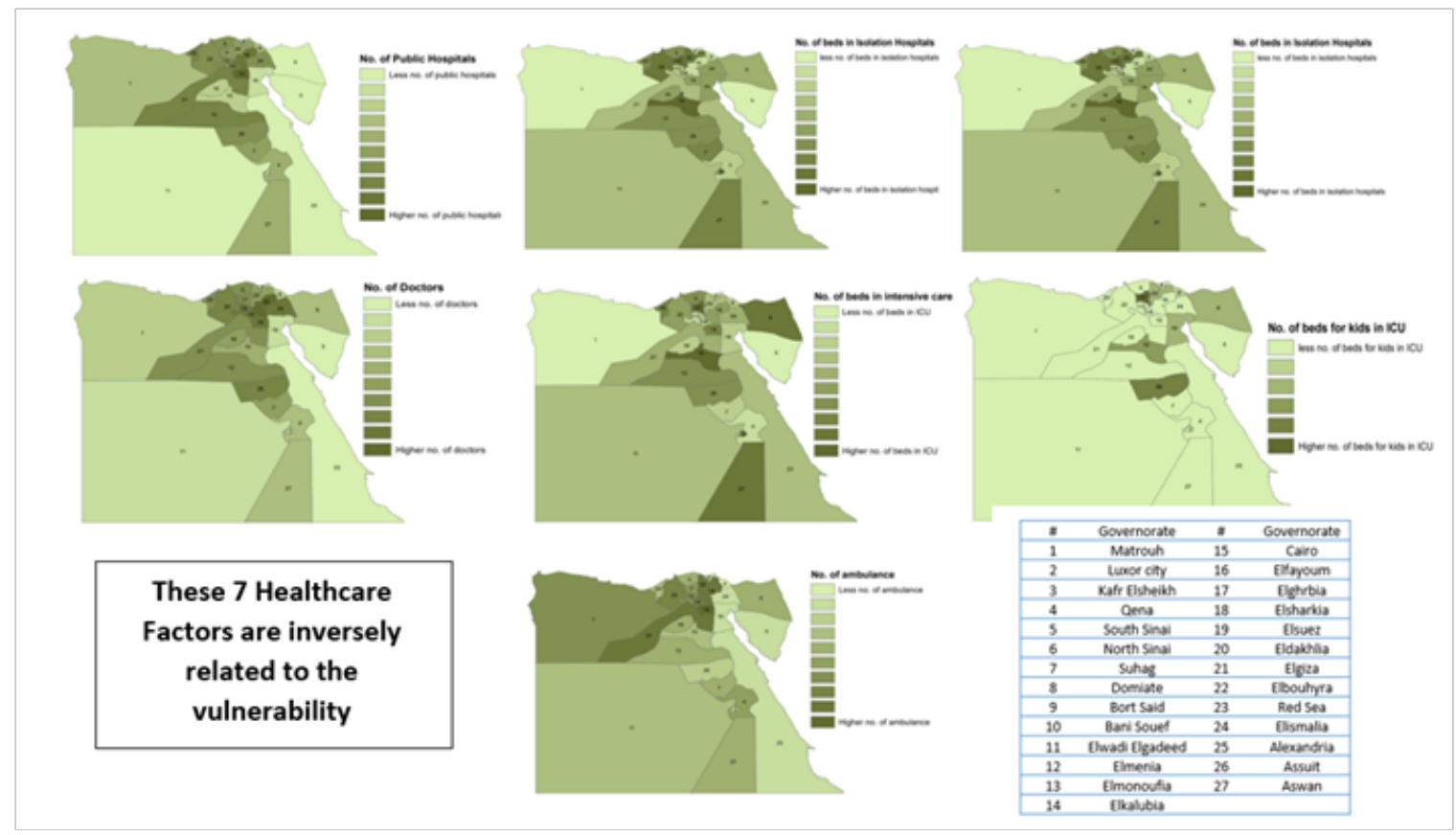

Fig. 3: Healthcare levels of vulnerability across Egypt

Determining the relative threats that face every governorate will help direct the distribution of resources as the pandemic grows. The following are key findings deduced from the GIS maps:

- Urban population: Governorates with higher urban populations face a challenge of creating awareness and isolating at-risk people.

- Density rate: Highly densely populated urban areas establish conditions under which COVID-19 can spread rapidly and remain unrecognized in highly density cities.

- Illiteracy and unemployment rate: high illiteracy rate is usually correlated with high unemployment rate

- Healthy housing: inadequate access to water and sanitation in an informal house are usually correlated with the level of poverty. Egyptians living in extreme poverty reached $32.5 \%$ of Egyptian in $2018^{[16]}$

- Number of registered private vehicles: limited cities (basically, greater Cairo) owned most registered private vehicles. Indicating that most Egyptian depend on public transportations.

- The capacity of a public health system: it is crucial to detect, isolate and manage COVID 19 infected persons and, ultimately, to minimize their social impacts, especially in densely populated areas. The safety of health workers with a very poor health system is a very important priority since these professional professionals are an important part of maintaining the services. There is a relatively insufficient number of doctors and hospital beds. Such public health systems will face the spread of COVID 19 with minimal tracking and testing leading to accelerating its transmission. This makes sharing information and raising awareness a crucial task.

- Examining the GIS maps reflecting the 16 risk factors considered revealed that a handful of governorates -Greater Cairo, Aswan, Assuit, and Bahira- are at the highest level of risk for almost all risk factors. This multilayered risk portfolio emphasizes the vulnerability of these governorates and the importance of attempting to detect and restrict the transmission of the disease at the primary stage until it is embodied in urban or displaced person's high densities areas. Luckily, a few governorates, like El Wadi El Gedid, have relative less high-risk vulnerabilities and a variety of positive factors.

\section{IV.2.1. Composite index}

The EFA has defined the common variance within a series of variables observed and produces three factors that include this common variance. These three scores have shown $78 \%$ of the data variance and have been measured using a linear equivalent to a weighted percentage of each of the variables used in the study. The degree of variance in comparison with the other variables is the amount of the contribution of each variable. The authors named all three of them and realized that the first score named "Socio demographic factors" managed to explain $44 \%$ of the common variance. The GIS map for this composite score matches the pattern of infection. 
Table 3: Rotated component matrix

\begin{tabular}{|c|c|c|c|}
\hline \multicolumn{4}{|c|}{ Rotated Component Matrix } \\
\hline & \multicolumn{3}{|c|}{ Factor Loadings } \\
\hline & $\begin{array}{l}\text { Demographic and general } \\
\text { healthcare conditions }\end{array}$ & Environmental conditions & Critical care conditions \\
\hline Density rate & .943 & & \\
\hline Illiteracy rate & & .842 & \\
\hline Unemployment rate & .797 & & \\
\hline $\begin{array}{l}\# \text { of Houses not connected to } \\
\text { sewage }\end{array}$ & & .956 & \\
\hline $\begin{array}{l}\text { \# of Houses not connected to } \\
\text { water }\end{array}$ & & .884 & \\
\hline \# of Informal-housing & & .733 & \\
\hline Poverty rate & & .706 & \\
\hline \# of Privately owned vehicles & .981 & & \\
\hline \# of Public hospitals & .925 & & \\
\hline \# of Beds at public hospitals & .950 & & \\
\hline \# of Beds for isolation & & & .872 \\
\hline \# of ICU beds & & & .902 \\
\hline \# of ICU beds for kids & & & .805 \\
\hline \# of Registered doctors & & .637 & \\
\hline \# of Ambulance cars & .771 & & \\
\hline
\end{tabular}

Source: original output of SPSS - conducted by the researchers

Figure 4 shows the first factor titled "Socio-demographic Factor' matched the pattern of case infection published in May 2020. This match indicates that is it not only about availability of medical services only, but about prevailing of certain demographic factors as well. we will explore these findings in the following section.

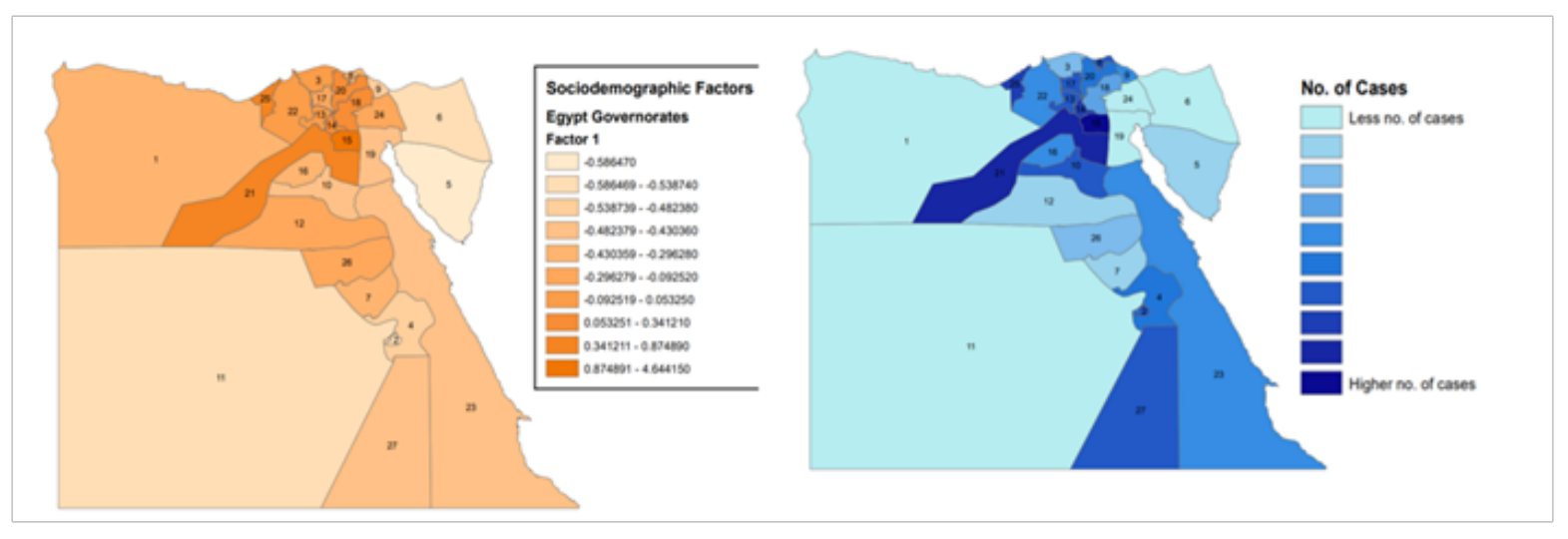

Fig. 4: Pattern matching between the spread of COVID-19 in May 2020 and the Sociodemographic Factors 


\section{IV.3. Decisions affecting disease transmission}

This part of the article contains decisions to control disease transmission during the pandemic. It concentrated on quarantine strategies on social distance up to the end of the outbreak. The authors reviewed the effects of certain demographic, environmental and health factors on COVID-19 cases in Egypt. They discussed the remaining uncertainties on the infectiousness and transmissibility of COVID-19. In real life, because there are differences in demographic, economic and health factors across a country, the population is not divided by rules evenly. Some governorates in our might be less fortunate than others. For example, individuals living at high density areas have a higher probability infected than others not living in such high-density areas. Social distance is intended to decrease the spread of viral diseases from infected individuals to vulnerable people by increased physical distance or decreased frequency in dense populations, such as schools or places of work ${ }^{[17]}$. It is a non-healthcare measure that was identified by Qualls et al. in 2017 to increase usage of remote and telecommuting options, staggering work hours and further spacing employees are included. The authors used the number of owned vehicles as a proxy variable for $\mathrm{it}^{[18]}$. The rational is that people with private cars will be more probable to maintain social distancing. Since the authors cannot directly measure the implementation of social distancing, they measured the proxy variable instead. The authors also investigated the effect of various demographic, environmental and heath factors (independent variables) on the number of casas of COVID 19 occurred in 2nd of May 2020. Linear regression analysis was used to investigate how much of the variation in the dependent variable (number of casas of COVID-19 occurred in 2nd of May 2020) can be explained by the independent variables.

\section{IV.3.1. Risk Factors Linked to Initial Stage of Reported Cases}

The pattern of reports of COVID-19 in May 2020 in Egypt is important depending on the context of each risk factor is highly correlated with just six indicators arranged in this order: Private vehicles (0.885), density (0.835), beds at public hospitals (0.763), Public hospitals (0.739), unemployment (0.722) and \# of ambulance (0.647) as shown in Table 4.A clear case of Multi-collinearity was identified between \# of owned Private vehicles and the rest of the variables. 


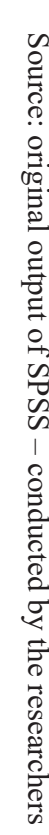

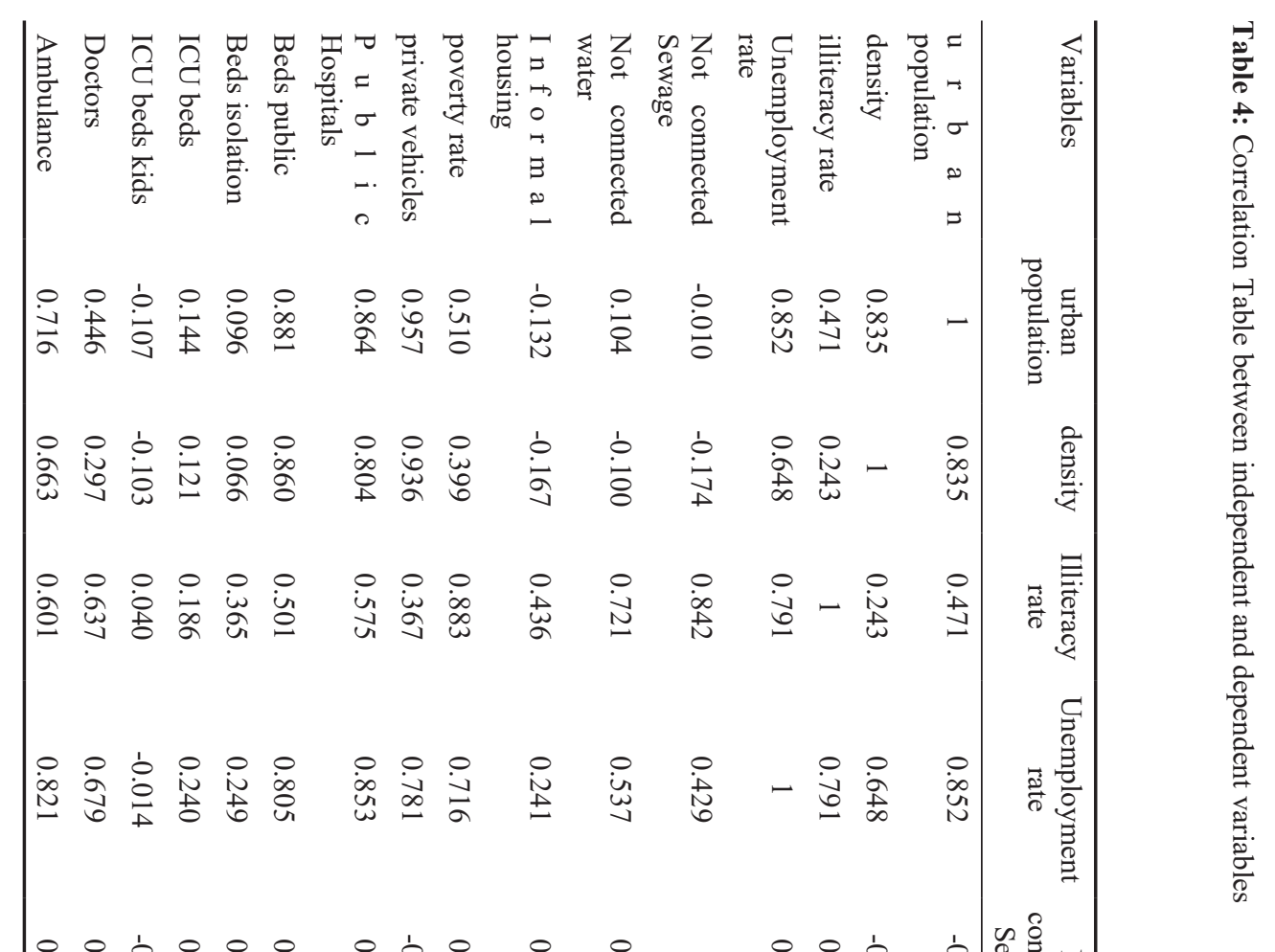

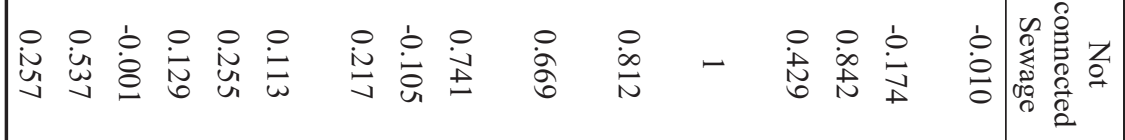

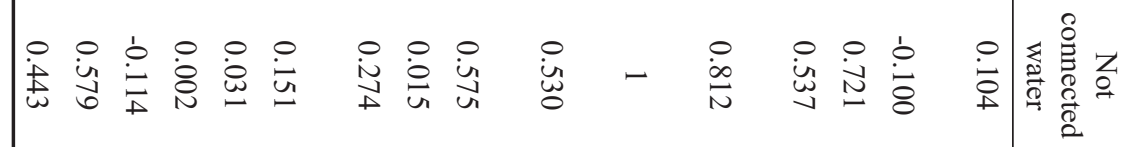

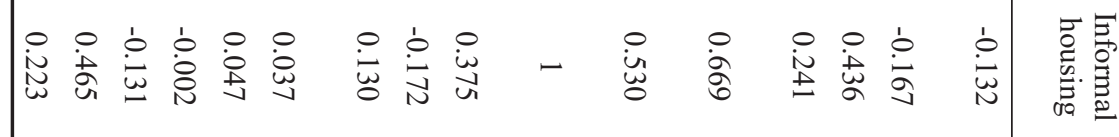

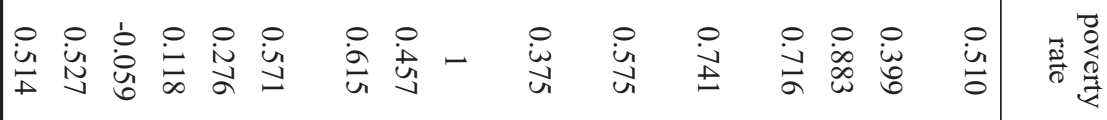

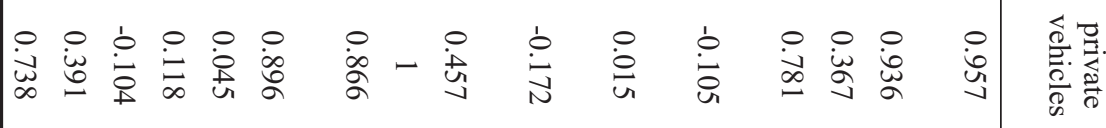

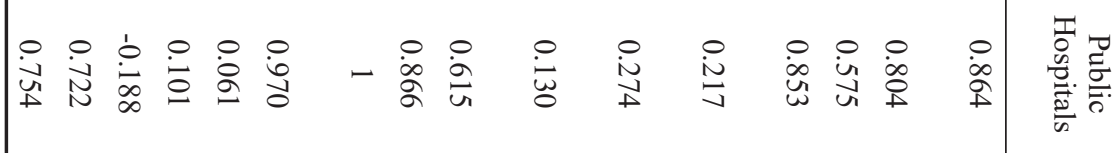

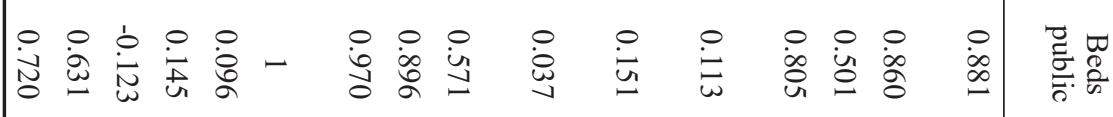

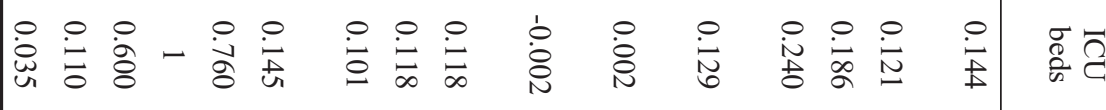

官家

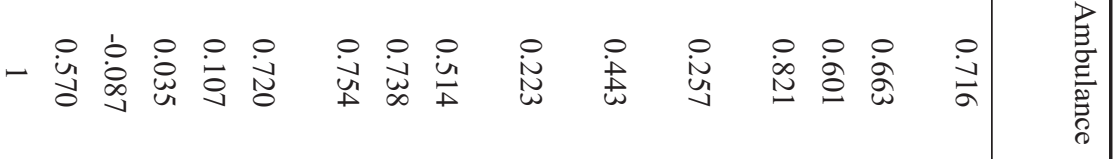


IV.3.2. Assessment of Risk Factors for Next Phase.

Moving forward, it was very important to identify the key indicators affecting the spread of COVID-19 in Egypt. The researchers conducted a stepwise regression and the

Table 5: Output of step wise regression

Model Summary

\begin{tabular}{|l|l|l|l|l|l|}
\hline Model & R & R Square & Adjusted R Square & Std. Error of the Estimate & Durbin-Watson \\
\hline 1 & $.885 \mathrm{a}$ & .784 & .775 & 110.3872 & 1.810 \\
\hline
\end{tabular}

a. Predictors: (Constant), private vehicles

b. Dependent Variable: Number of Patients in May

adjusted $\mathrm{R}$ squared was $77.5 \%$ with only one variable that is the proxy variable. The model was significant, and the model managed to explain $77 \%$ of the change in the dependent variable using only one variable (\# of private cars).

\begin{tabular}{|cl|r|r|r|r|r|}
\hline \multicolumn{1}{|c|}{ ANOVA $^{\text {a }}$} \\
\hline \multirow{2}{*}{ Model } & \multicolumn{1}{|c|}{$\begin{array}{c}\text { Sum of } \\
\text { Squares }\end{array}$} & df & Mean Square & F & Sig. \\
\hline 1 & Regression & 1103923.794 & 1 & 1103923.794 & 90.594 & $.000^{\text {b }}$ \\
& Residual & 304633.613 & 25 & 12185.345 & & \\
& Total & 1408557.407 & 26 & & & \\
\hline
\end{tabular}

a. Dependent Variable: Number_Patients_May

b. Predictors: (Constant), private vehicales

\begin{tabular}{|c|c|c|c|c|c|c|}
\hline \multicolumn{7}{|c|}{ Coefficients $^{\mathrm{a}}$} \\
\hline \multirow{2}{*}{\multicolumn{2}{|c|}{ Model }} & \multicolumn{2}{|c|}{ Unstandardized Coefficients } & $\begin{array}{l}\text { Standardized } \\
\text { Coefficients }\end{array}$ & \multirow[b]{2}{*}{$\mathrm{t}$} & \multirow[b]{2}{*}{ Sig. } \\
\hline & & $\mathrm{B}$ & Std. Error & Beta & & \\
\hline \multirow[t]{2}{*}{1} & (Constant) & 101.622 & 23.949 & & 4.243 & .000 \\
\hline & private vehicales & .001 & .000 & .885 & 9.518 & .000 \\
\hline
\end{tabular}

\section{a. Dependent Variable: Number_Patients_May}

Source: original output of SPSS - conducted by the researchers

Then the researchers wanted to explore what could the second important factor affecting the spread of COVID 19, so we removed the proxy variable from the data set and repeated the stepwise regression. This model managed to explain $83 \%$ of the change in the dependent variable using only two variables (density and urban population).

\begin{tabular}{|l|l|r|r|r|}
\hline \multicolumn{5}{|c|}{ Model Summary } \\
\hline Model & R & R Square & $\begin{array}{c}\text { Adjusted R } \\
\text { Square }\end{array}$ & $\begin{array}{c}\text { Std. Error of } \\
\text { the Estimate }\end{array}$ \\
\hline 1 & $.835^{\mathrm{a}}$ & .697 & .685 & 130.7232 \\
2 & $.916^{\mathrm{b}}$ & .839 & .825 & 97.3226 \\
\hline
\end{tabular}




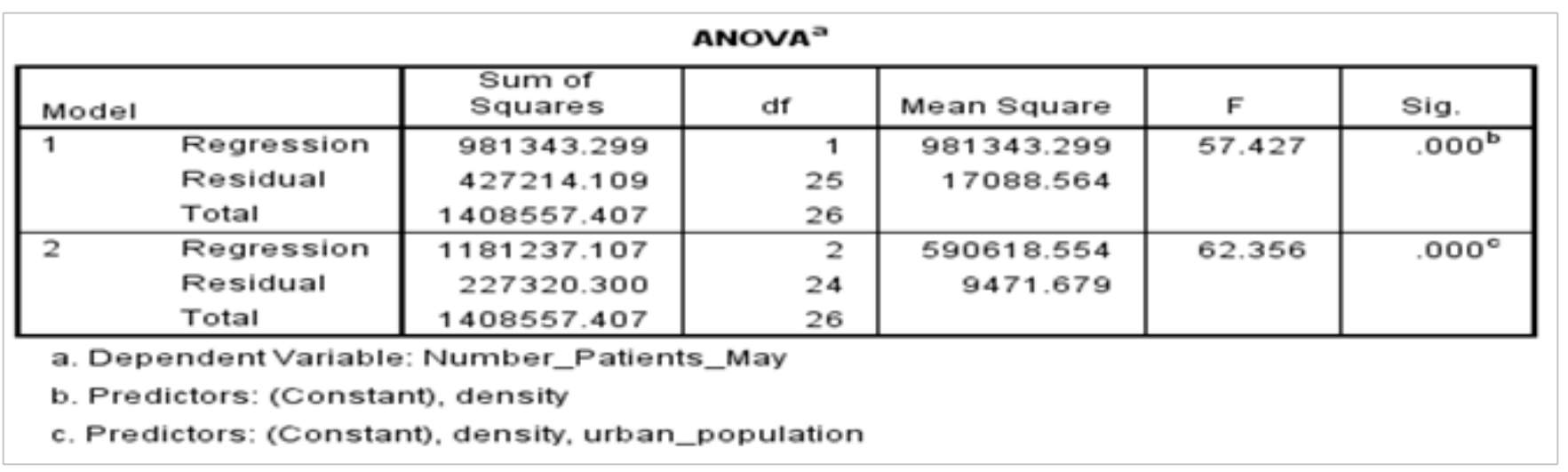

Table 6: Stepwise regression Model after eliminating the most influential factor in the previous step

\begin{tabular}{|c|c|c|c|c|c|c|}
\hline \multicolumn{7}{|c|}{ Coefficients $^{a}$} \\
\hline \multirow{2}{*}{\multicolumn{2}{|c|}{ Model }} & \multicolumn{2}{|c|}{ Unstandardized Coefficients } & \multirow{2}{*}{$\begin{array}{c}\text { Standardized } \\
\text { Coefficients } \\
\text { Beta }\end{array}$} & \multirow[b]{2}{*}{$\mathrm{t}$} & \multirow[b]{2}{*}{ Sig. } \\
\hline & & $\mathrm{B}$ & Std. Error & & & \\
\hline \multirow[t]{2}{*}{1} & (Constant) & 122.921 & 27.488 & & 4.472 & .000 \\
\hline & density & .020 & .003 & .835 & 7.578 & .000 \\
\hline \multirow[t]{3}{*}{2} & (Constant) & 46.536 & 26.368 & & 1.765 & .090 \\
\hline & density & .021 & .002 & .853 & 10.390 & .000 \\
\hline & urban_population & $6.401 \mathrm{E}-7$ & .000 & .377 & 4.594 & .000 \\
\hline
\end{tabular}

a. Dependent Variable: Number_Patients_May

Source: original output of SPSS - conducted by the researchers

IV.4. Build the AI Model for COVID-19 Outbreak in Egypt

IV.4.1. Preparing the Data

After normalizing the COVID-19 data, it was multiplied by a scale of 100 to enlarge the numbers to be able to fit the model. Then the data was divided into $80 \%$ training and $20 \%$ test. We first trained the model for US data, then prepared and trained the same model for Egypt's data. After obtaining the results, we tuned the hyperparameters

Table 7: The model architecture and configuration parameters and retrained the model for US and Egypt data again. Moreover, we trained the model on worldwide data then used it to predict Egypt data to get better accuracy.

IV.4.2. Model Architecture:

A deep neural network architecture has been developed to predict the future new cases numbers of COVID-19 in Egypt. The model architecture and configuration parameters are as follows:

\begin{tabular}{|c|c|c|}
\hline Loss & Mean absolute error & Coavolution Lyer \\
\hline Optimizer & Adam & \\
\hline Batch size & 5 & Relu \\
\hline Activation & $1 \mathrm{e}-8$ & \\
\hline Leaming rate & 100 & \\
\hline N. of Epochs & Mean absolute error & \\
\hline Metrics & 10 & \\
\hline Window size & & \\
\hline
\end{tabular}




\section{IV.4.3. Results for Deep Learning Model}

The results for the initial hyper parameter were bad and the model gave high mean absolute error. From the data analysis, we recognized that there are countries that are in a similar condition to Egypt. Different analysis techniques gave different results about the countries that are supposed to be like Egypt to take as a reference for the future of COVID-19 in Egypt. The countries were Slovenia, Iraq, and Iran.The model was tested on Egypt data and gave the following results:

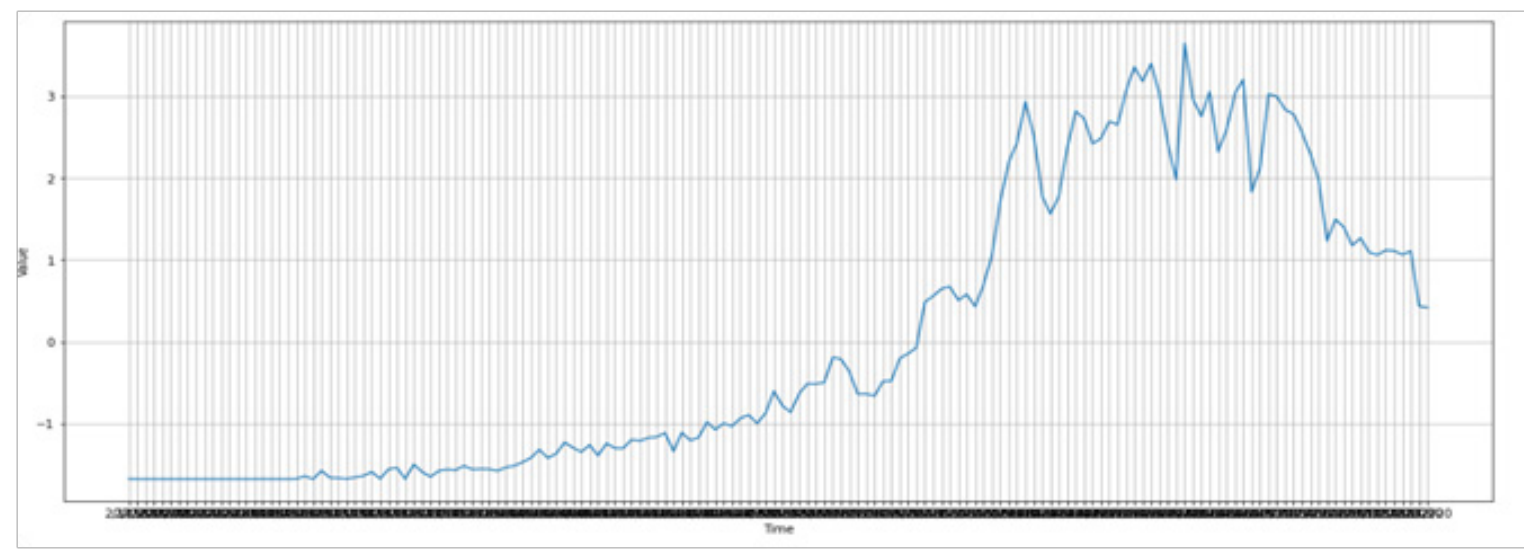

Fig. 5: Egypt data plotting

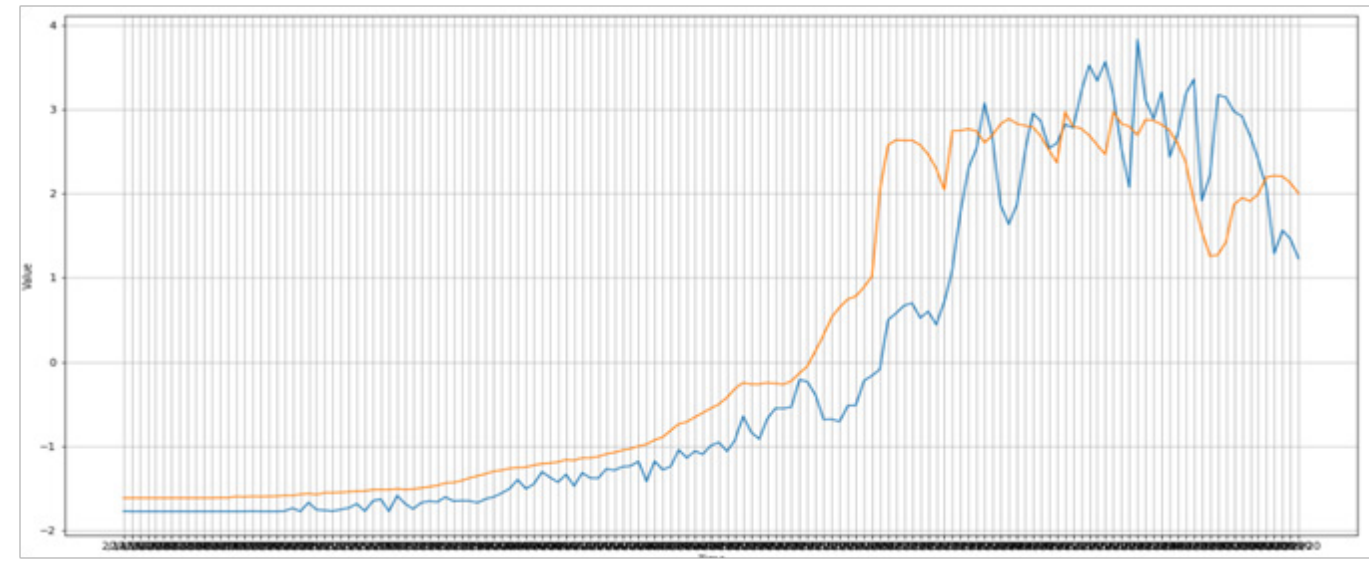

Fig. 6: Egypt data on training phase

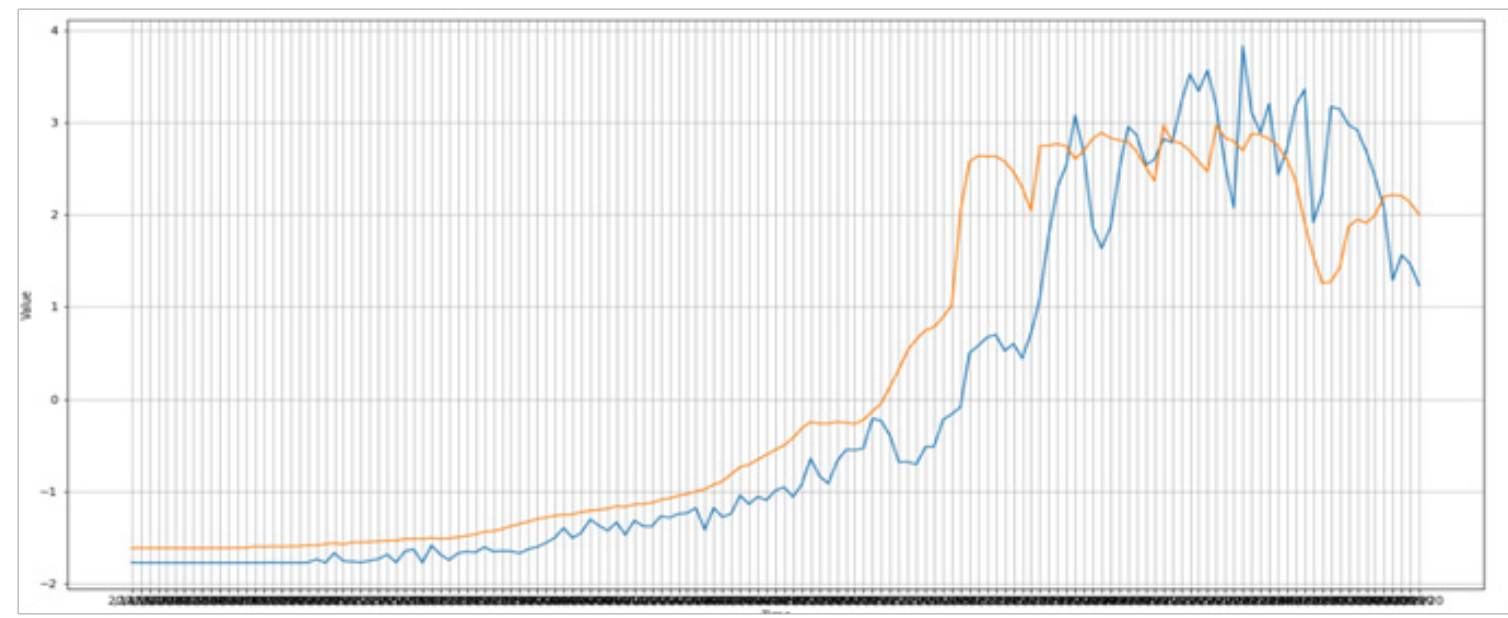

Fig. 7: Egypt data on validation phase 
IV.5. Build a Secure Network of COVID-19 Outbreak using Blockchain

In this part, we developed and implemented our architecture on a larger scale to cover the African countries, which simulate the Egyptian governorates while Africa simulates Egypt.

\section{IV.5.1. Goals}

- Understand how blockchain models are implemented and how beneficial they are.

- Draw the blockchain architecture while pinpointing the miner nodes and storage nodes.

- Build a Proof-of-Work to showcase the implemented private blockchain architecture.

\section{IV.5.2. Selection of mining nodes in the architecture.}

Choosing the miner nodes is a significant step since it gives an idea about the design's real-world interpretation. In selecting the place of miner nodes, two different methodologies have been followed while keeping in mind that there should be a replacement in case a node fails. The first followed methodology was getting the map of Africa and selecting countries that are distributed over the continent and can provide good coverage for counties around it. The coverage depends on how well the ICT composite index, composite electricity index, and overall, the Africa infrastructure development that is produced by the African Development Bank. Therefore, countries with the highest score in ICT and electricity were the main list, from here, these countries were allocated on the map to select from it some countries distributed all over the continent, according to the Africa Infrastructure knowledge program. The countries with the highest ICT index are South Africa, Mauritius, Seychelles, Morocco, Tunisia, Algeria, and Egypt.

After taking in consideration the results of both methods and the countries that were common, they have stability and are distributed among the continent.

The Chosen Miner nodes are:

- Egypt,

- South Africa,

- Moroco, and

- Gabon.

IV.5.3. Selection of the blockchain architecture.

Figure 8 shows an overview of the nodes in Africa. 4 nodes are chosen as "miner" nodes (will be explained later) based on which 4 countries possess the most advanced electricity and IT infrastructure as well as political stability.

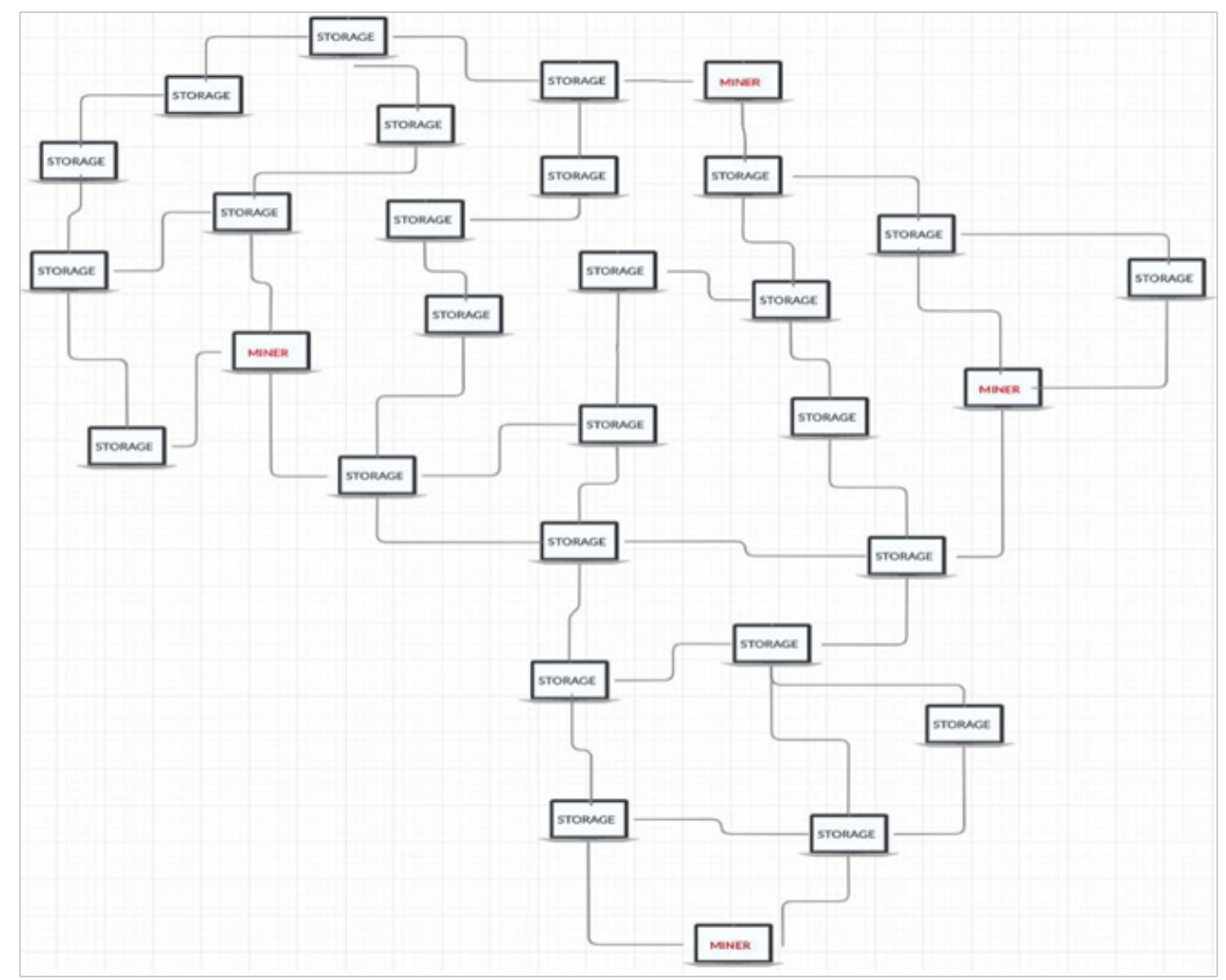

Fig. 8: Overview of nodes in the blockchain. Four nodes are chosen as miners across Africa 


\section{VI.5.4. Nodes Communication through the Network}

The connections between nodes refer to the fact that each node knows information about its neighbor nodes enough to send, receive, verify a transaction with them. This information is:

- IP address, to connect to a neighbor node.

- Public key, to verify any block issued by that node.

\section{IV.5.5. Block Mining}

Security is obtained in blockchain-based applications, like this one, through block mining. Block mining is a concept that means that each new block is added to the chain only if the node responsible of adding new blocks to the chain "proved" to have consumed computational power. One popular algorithm to mine blocks is called "proof of work".

Sabaa, and Elsheikhb (2020), have applied two algorithms to model the cumulative COVID-19 cases in Egypt and predict them during (1 March - 10 May of 2020). They use the statistical-based ARIMA and Artificial Intelligent NARANN, both algorithms rendered fairly good results but in comparison with ARIMA, NARANN showed improved results.

Their output matches the above-mentioned results obtained using different statistical-based tools. The findings of this study will enable policymakers to adopt short-term tactics to reduce the epidemic's spreading. The following policies may be:

- Changing the overnight curfew period to limit social contact and to implement more strict quarantine measures.

- Suspending public transportation between Egyptian governorates and operating additional trains and buses to limit overcrowding.

- The construction of more field hospitals for quarantine.

- Extending the closing time of schools, colleges and mosques and limiting all social meetings seriously.

- Supporting irregular workers with exceptional grants $^{[19]}$.

\section{September 2020: Robound or Second wave}

As per the spokesman of the Health Ministry Dr. Khaled Megahed, the ministry witnessed an increase in the number of daily infected patients ranging between 100-200 daily cases following a clear consistent downward trend. Therefore, the Health Ministry reactivated the plan for coexistence with the coronavirus applying precautionary measures in institutions and forcing everyone to wear masks on the streets and in public transportation.

This spike reflects the reckless behaviour of Egyptians during five-day Eid Al-Adha holiday. This holiday is usually marked by family gatherings disregarding of the protective measures. So, we believe that it is probably a rebound of the first wave due to its minor incremental increase.

A rebound usually witnesses a $20 \%$ increase in number of infections due to the exhaustion of susceptible individuals, but all explanations remain hypotheses when we talk about novel COVID-19.

According to Miss Manal Salama, coordinator of the Health Ministry's coronavirus committee, necessary precautions against the virus must be taken, and that all citizens must not be present in any public facilities without wearing masks and adopting social distancing measures ${ }^{[20]}$.

\section{March 2021: Mid of the third Wave}

As per Dr. Ashraf Hatem, head of the health committee that: we are heading towards the beak of third wave sooner than expected, and the degree of its severity would be determined by the extent of people's adherence to anticoronavirus measures. He also said that the best prevention technique remains wearing face mask and maintain social distance.

According to a study conducted by CAPMAS covering Q4 2020:

- Cairo had the largest number of coronavirus infections

- Alexandria had the largest death toll.

- North Sinai came first in terms of number of deaths to infected cases

The reason behind theincreasing growth rates of infections was related to wrong irresponsible behaviours of some citizens in the form of increased contact, and failure to adhere to the precautionary measures. Accordingly, the government lowered the attendance of employees at workplace and banned weddings in closed halls.

Another proof that social distancing is the key factor to control the spread of this pandemic.

\section{CONCLUSION}

The COVID-19 pandemic poses multiple research questions. Further study is needed to model studies to help generate target responses to COVID 19 and other outbreaks. The number of needed decisions is enormous making it very important to integrate various studies to maximize the benefits of simulation modelling in reducing the impact of COVID-19 globally.

\section{FUTURE WORK}

The quality of hospital management is important in terms of patient length of stay. The resources in hospitals are scarce and the use of bed and time by the clinician is effective. A model capable of predicting patient durations will help evaluate the variables that most impact on the length of stay in hospitals. Artificial intelligence (AI) may aid in three main areas: forecasting, diagnosis, and treatment. In principle, AI can also be used to predict the coronavirus growth, but the authors do not yet have enough information to simulate the virus this time around ${ }^{[21]}$.

No potential conflict of interest was reported by the authors. 


\section{REFERENCES}

[1] www.worldometers.info/coronavirus/ last access 3March 2021.

[2] S. Smith, "Managing Health and Economic Priorities as the COVID-19 Pandemic Spreads through Africa," Spotlight, Africa Center for Strategic Studies, March 30, 2020.

[3] Africa Center for Strategic Studies, "Five Myths about Coronavirus in Africa," Spotlight, March 27, 2020.

[4] W. Williams, "COVID-19 and Africa's Displacement Crisis," Spotlight, Africa Center for Strategic Studies, March 25, 2020.

[5] Africa Center for Strategic Studies, "Coronavirus Spreads through Africa," Infographic, April 8, 2020.

[6] S. Smith, "What the Coronavirus Means for Africa," Spotlight, Africa Center for Strategic Studies, February 4, 2020.

[7] Central Agency for Public Mobilization and Statistics - retrieved June 2020- www.capmas.gov.eg

[8] Zhou C et al., "COVID-19: Challenges to GIS with Big Data", Journal of Geography and Sustainability, 77:78, 2020.

[9] Palaniyandi M., "GIS for rapid epidemiological mapping and health care management with special reference to filariasis in India", International journal of medical science and Public Health, 2015.

[10] https://www.ibm.com/analytics/spss-statistics-software.

[11] Ozgur C. Kleckner M. and Li Y,"Selection of Statistical Software for Solving Big Data Problems: A Guide for Businesses, Students, and Universities", SAGE Open April-June 2015: 1-12.

[12] Howell D, "Fundamental Statistics for the Behavioral Sciences", 8th Edition. Cengage Learning, 2013.

[13] OECD, "Quality Framework and Guidelines for OECD Statistical
Activities", 2003a. available on www.oecd.org/statistics.

[14] Loughnan M., Nicholls N., and Tapper N, "Mapping Heat Health Risks in Urban Areas", International Journal of Population Research, Vol 2012, Article ID 518687, 12 pages, 2018.

[15] Demographic and environmental levels of vulnerability across Egypt. [16] Yongjian Z. and Jingui X."Association between ambient temperature and COVID-19 infection in 122 cities from China", Science of The Total Environment, 2020.

[17] Ahmed F, Zviedrite N, Uzicanin A., "Effectiveness of workplace social distancing measures in reducing influenza transmission: a systematic review", BMC Public Health, 18: 518, 2018. doi: 10.1186/s12889-018-5446-1

[18] Qualls N, Levitt A, Kanade N, Wright-Jegede N, Dopson S, Biggerstaff $\mathrm{M}$, et al., "Community mitigation guidelines to prevent pandemic influenza - United States, 2017", Morbidity and Mortality Weekly Report Recommendations and Reports, 66:1-34,2017. doi: 10.15585/mmwr.mm6601a1.

[19] Saba, A.I. and Elsheikh, A.H., "Forecasting the prevalence of COVID-19 outbreak in Egypt using nonlinear autoregressive artificial neural networks", Process Safety and Environmental Protection, 2020.

[20] Egypt Care, "The most prominent statistics of the current situation to combat the emerging corona virus in Egypt compared to the world", 2020.https://www.care.gov.eg/EgyptCare/Index.aspx.

[21] Heaven, W. D., 2020. AI could help with the next pandemic — but not with this one. MIT Technology Review.https://www.technologyreview. com/2020/03/12/905352/ai-could-help-with-the-next-pandemicbut-notwith-this-one/ 